\title{
Comparative Effect of Maitake Pro4x with Chemotherapy Breast Cancer Treatment
}

\section{Diego Aguilera Braico ${ }^{1}$, Agustina Roldan-Deamicis ${ }^{2}$, Belén Brie ${ }^{2}$ and Gabriela Andrea Balogh ${ }^{2^{*}}$}

${ }^{1}$ Department of Health Sciences, National University of the South, San Juan, Bahia Blanca, Buenos Aires, Argentina

${ }^{2}$ Faculty of Medical Sciences, Institute of Biomedical Research, Catholic University Argentina - UCA - CONICET, Buenos Aires, Argentina

"Corresponding author: Gabriela Andrea Balogh, Ph.D., Department of Health Sciences, National University of the South, San Juan 671 Of 1, Bahia Blanca-8000, Buenos Aires, Argentina, Tel: 215-728-5288; E-mail: ga_balogh@yahoo.com

Received date: October 20, 2016; Accepted date: March 03, 2017; Published date: March 07, 2017

Copyright: $\odot 2017$ Braico DA, et al. This is an open-access article distributed under the terms of the Creative Commons Attribution License, which permits unrestricted use, distribution and reproduction in any medium, provided the original author and source are credited.

\begin{abstract}
Background: Conventional treatments for breast cancer involve surgery followed by radiation and hormonal therapy and/or chemotherapy. Some of these treatments have toxic side effects. Because drugs used in chemotherapy affect both cancer and normal cells to varying degrees, researchers are currently developing targeted drugs that only attack cancer cells without affecting normal cells. One approach to this is to found compounds that are more selective and specific, destroying only tumour cells and prevent metastases without harming normal cells. For thousands of years, medicinal mushrooms have been used because of their healing properties. Maitake (Grifola frondosa) is one of the most promising edible and medicinal mushroom, acting promoting the immune system against the tumorigenesis process.
\end{abstract}

Methods: In the in vitro studies, we measured and compared the effect of Maitake Pro4X or Chemotherapy on LM3 Breast Tumour Cells death. Increased concentrations and different time of treatments were employed. In the in vivo studies, we employed breast tumour bearing female BALBc mice 6-8 weeks old, to assayed the effect of Maitake Pro4X with or without chemotherapy measuring the tumour volume, mortality, relative survival and size of tumour necrosis area after treatment.

Results: After 5 weeks of treatment in tumour-bearing BALBc mice, we observed that Maitake Pro4X significantly increased the overall survival of animals and reduced the malignancy of breast tumours. We also found that Maitake Pro4X, as chemotherapy, induce cell-death in a dose and time dependent form.

Conclusion: The beneficial effects of Maitake D-Fraction Pro4X, if supported by further evidence could be useful for the treatment of cancer patients to reduce the adverse effects of the conventional chemotherapy treatment.

Keywords: Breast cancer; Maitake Pro4X; Chemotherapy; Cancer treatment

\section{Introduction}

Breast cancer is the second most common cancer in the world today. The approach to treating breast cancer should involve a holistic view of the patient, which requires a multidisciplinary treatment team [1]. When cancer becomes metastatic, the goal of treatment is palliative, aiming to prolong survival and to improve the patient's quality of life. Although the average survival rate is low overall, some women with breast cancer may survive longer [2]. Treatment is usually divided into standard chemotherapy and targeted therapy [3].

Chemotherapy is used for several purposes: to cure cancer, to prevent the spread of cancer, to remove metastatic cells, and to reduce symptoms to improve patients' quality of life when a cure is not possible [4]. Chemotherapy works by taking advantage of the increased sensitivity to treatment of rapidly dividing cells; accordingly, it affects not only cancer cells but also normal actively dividing cells, including cells of the bone marrow, the digestive tract and hair follicles [5]. This lack of specificity explains some of the common side effects such as myelosuppression, mucositis and alopecia [6-8]. In addition to its low specificity, chemotherapy is also limited as a treatment method due to development of drug resistance by cancer cells. Doxorubicin, isolated from a mutant Streptomyces peucetius, is an antibiotic in the anthracycline family $[9,10]$. Doxorubicin is a cytotoxic chemotherapy used to treat various cancers, including breast cancer, and it has a broader and more efficient spectrum against tumours than its predecessor, adriamycin. Doxorubicin inhibits tumour cell proliferation by mechanisms that lead to DNA disruption $[4,9]$. Free radical formation is also involved in DNA breakage and in cellular lipid peroxidation, cell membrane disruption and protein kinase $\mathrm{C}$ (PKC) activation, which induces apoptosis [11]. Like any chemotherapy drug, doxorubicin has adverse effects, including a dosedependent cardiotoxic effect $[9,12,13]$. This toxicity is related to the release of free radicals, which are responsible for oxidative stress, leading to lipid peroxidation, protein degradation and cell membrane damage by proteins, carbohydrates and DNA radicals, among other adverse effects [14]. Cyclophosphamide is an alkylating agent in the oxazaphosphorine group that has cytotoxic and immunosuppressive activities $[15,16]$. It's not only inhibits tumour cell multiplication but also may act on blood cells, producing adverse effects. Alkylating agents are thought to exert their immunosuppressive activity by inhibiting nuclear DNA replication. A hydrogen atom is replaced by an alkyl group, preferably at the N7 nitrogen of guanine, thus blocking 
DNA replication and transcription and leading to cell death $[4,16]$. Cyclophosphamide is a carcinogen that can cause secondary tumours [17]. It has been shown to cause genetic mutations in somatic cells; chromosomal aberrations, micronucleus formation and sister chromatids exchange have also been observed [17]. The adverse effects of cyclophosphamide are more frequent with prolonged treatment; however, most of these effects are reversible if detected early.

In Asia, mushrooms are traditionally consumed for their nutritional and medicinal properties, which were described as early as 2,700 B.C. [18]. It is believed that only $10 \%$ of the estimated 140,000 species of fungi on Earth have been identified. It is further estimated that only $5 \%$ of these species have known pharmacological properties [19]. The production of biologically active metabolites by fungi represents a very broad and promising field of study, which, until now, has received little attention. Among the metabolites produced by fungi are antifungal, antimicrobial, antiviral, and cytostatic agents and enzymes that regulate growth $[20,21]$. Maitake is an edible and medicinal mushroom; its extracts possess $\beta$-glucans with different degrees of purification and have antitumor properties [22]. $\beta$-glucans in mushrooms have a central straight chain of D-glucose moieties linked together by $\beta-1,3$ glucans and with side branches of $\beta-1,6$ glucans of various sizes. The $\beta$-glucans exert effects on the immune system, stimulating phagocytic activity by activating leukocytes and inducing the production of various cytokines, which could be responsible for their antitumour activity $[23,24]$. The oral administration of extracts derived from $\beta$-glucans of the medicinal mushroom Grifola frondosa (Maitake) has been shown to stimulate haematopoiesis and immune cells recovery post-paclitaxel treatment in animal models [25]. $\beta$ glucans act on a variety of receptors in the immune system, particularly on CR3 and Dectin-1, thereby triggering a broad spectrum of immune responses [26]. $\beta$-glucans target immune cells, including macrophages, neutrophils, monocytes, natural killer (NK) cells and dendritic cells [26]. The immunomodulatory functions induced by $\beta$ glucans involve innate and adaptive immune responses. However, the exact mechanisms of immune system activation mediated by $\beta$-glucans remain unknown.

In the present work, we studied the effects of Maitake D-Fraction Pro4X in the treatment of mammary carcinogenesis in BALBc mice. Today, given the limitations of conventional therapies to reduce mortality from cancer, many efforts have focused on preventing carcinogenesis. In this context, the use of immunopotentiators, immune initiators or biological response modifiers (BRMs) that are capable of stimulating the immune cells that can identify tumour cells as foreign, eliminate and prevent carcinogenesis has gained prominence [11]. $\beta$-glucans are BRMs that, unlike conventional chemotherapeutic, activate or reinforce the host immune system, helping to kill tumour cells or inhibit tumour growth. Maitake fractions can fight cancer by slowing or stopping tumour growth and by preventing metastasis [27]. These fractions can also decrease the side effects of chemotherapy, including hair loss, pain and nausea, while enhancing their benefits [28]. The ability to avoid chemotherapy side effects would represent a breakthrough in the fight against cancer, as it would improve patients' quality of life and increase patient survival. It has been demonstrate that cancer patients receiving chemotherapy combined with Maitake showed improvements in some of the adverse effects of chemotherapy, including hair loss, nausea, vomiting, weight loss and leukopaenia. Maitake treatment was also found to reduce patients' pain [28]. One goal of the present work was to compare the cytolytic effect in murine mammary tumour LM3 cells in culture induced by Maitake Pro4x alone or in combination with chemotherapeutic drugs (doxorubicin and cyclophosphamide) at increased concentrations and at different times of treatment. The second aim of this work was to evaluate the effect of Maitake Pro4X on breast cancer treatment in mouse models, alone or in combination with chemotherapy, and to determine whether there is or not an adjuvant effect between both treatments.

\section{Materials and Methods}

\section{Maitake D-Fraction Pro4X}

Maitake D-Fraction Pro4X (Mushroom Wisdom Inc., N.J., USA) is an ethanol extract from the medicinal mushroom, Grifola frondosa, obtained under standard procedures performed by Mushroom Wisdom, Inc. Maitake D-Fraction Pro4X contains $100 \mathrm{mg} / \mathrm{ml}$ of DFraction, representing a $30 \%$ of active proteoglycan.

\section{LM3 cell cultures}

Tumourigenic LM3 cell line from metastatic mammary adenocarcinoma derived from BALBc mice were used in the in vitro studies. These murine cells lacked progesterone receptor (PR) and estrogen receptor (ER) expression [29]. The LM3 cells were kindly provided by Dr. Elisa Bal from Roffo Hospital, Buenos AiresArgentina. The cells were maintained with Minimum Essential Medium (MEM) (GIBCO) supplemented with $10 \%$ foetal bovine serum (FBS) at $37^{\circ} \mathrm{C}$ in a controlled atmosphere at $5 \% \mathrm{CO}_{2} /$ air and saturated humidity.

\section{Animal models}

Female 6-8-week-old BALBc mice were inbred at the Institute of Biomedical Research from Catholic University (UCA) Buenos Aires, Argentina. They were kept in special boxes with a controlled atmosphere and HEPA-filtered air at a controlled temperature of $22^{\circ} \mathrm{C}$ and with a 12-hour light-dark cycle. The animals were fed with special diet, and water was available ad libitum. We declare that all procedures performed in animal models were previously approved by the Ethical Committee of the Institute of Biomedical Research from the Medicine Faculty-UCA-Buenos Aires, Argentina.

\section{The effect of Maitake and/or chemotherapy on LM3 breast tumour cell death}

LM3 cultured cells were treat with increase concentrations of Maitake Pro4X $(0,36,91,183,267$ and $734 \mu \mathrm{g} / \mathrm{ml})$ and the experiment were performed by duplicate. LM3 cells were also treated with or without increase concentrations of Doxorubicine+Cyclophosphamide $(0,5,10,15,20$ and $40 \mu \mathrm{M}$ and $0,0.5,1.0,1.5,2.0$ and $2.5 \mu \mathrm{M}$, respectively). The effects on cell viability were evaluated at 24,48 and 72 hours of treatment.

\section{Determination of cell death}

LM3 cell death was determined at 24, 48 and 72 hours of treatment according to the method trypan blue exclusion test of cell viability/ death described in the literature [30]. 
Page 3 of 8

\section{In vivo experimental design and treatment}

The in vivo study included 30 female BALBc mice that were divided into 3 groups of 10 mice each: Group 1, Group 2 and Group 3. In all three groups, the tumourigenic process was induced by the intraperitoneal injection with approximately $4 \times 105$ LM3 murine breast tumour cells. Over the next 23 days, the mice were regularly checked. Starting on the 24th day, and for 35 days, the mice of Group 1 received $80 \mathrm{mg} / \mathrm{kg}$ of cyclophosphamide $+4 \mathrm{mg} / \mathrm{kg}$ doxorubicin weekly by oral administration. The mice of group 2 were given orally $5 \mathrm{mg} / \mathrm{kg}$ of Maitake Pro4X daily. The animals in group 3 received combined treatment, chemotherapy (cyclophosphamide+doxorubicin) weekly +5 $\mathrm{mg} / \mathrm{kg}$ of Maitake Pro4X daily (Figure 1). During the treatment period, the tumour size was weekly measured.

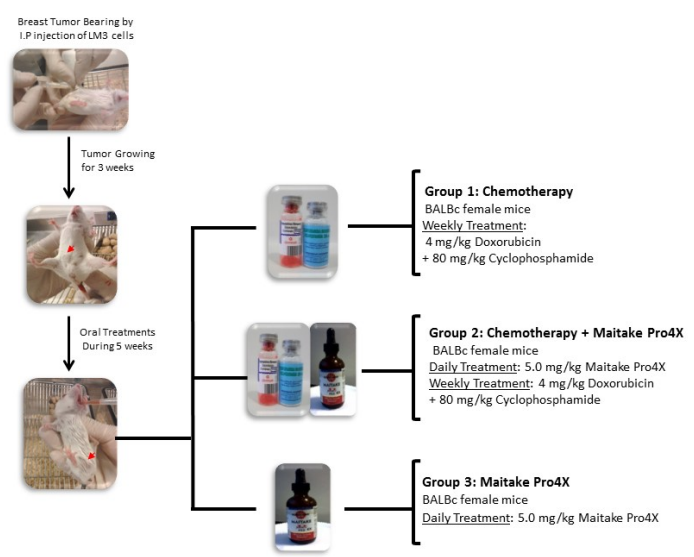

Figure 1: Schematic of the experimental design. This figure graphically shows the procedure that was followed in this project. 15 BALBc female mice were transplanted with LM3 tumoral cells to induce breast tumourigenesis. After 3 weeks, treatment procedures were performed for 5 weeks, mice were divided into three groups, Group 1: Chemotherapy, Group 2: Chemotherapy+Maitake Pro4X and Group 3: Maitake Pro4X, employing chemotherapy $(4 \mathrm{mg} / \mathrm{kg}$ doxorubicin $+80 \mathrm{mg} / \mathrm{kg}$ cyclophosphamide) or Maitake Pro4X (5.00 $\mathrm{mg} / \mathrm{kg}$ ) either alone or in combination.

\section{Tumor breast examination}

Animals were checked weekly by visual examination and by palpation of the abdominal-inguinal area to note the tumour appearance. Progressively growing masses with a mean diameter $>9$ $\mathrm{mm}(0.90 \mathrm{~cm})$ were regarded as tumour. The tumours were measured with a digital calliper in two perpendicular diameters, and the volume was calculated as $\left(\mathrm{X}^{2} . \mathrm{Y}\right) / 2$, where $\mathrm{X}$ and $\mathrm{Y}$ represent the smallest and largest diameters, respectively.

\section{Statistics analysis}

The effect of treatment was tested by analysis of variance (ANOVA) [31]. Differences among of means were assessed using Student's t-tests. Experiments were repeated by triplicate. Variability was expressed as the standard error of the mean (SEM). Differences were considered significant at $\mathrm{p}<0.05$.

\section{Results}

\section{Effect of Maitake Pro4X alone or in combination with chemotherapy on mammary tumourigenesis}

Similar tumour growth curves were observed in the treatment of breast tumorigenesis with Maitake Pro4X alone or in combination with chemotherapy (Figure 2A). At the beginning of treatment, the average tumour size was $0.94 \pm 0.21 \mathrm{~cm}$ in the group treated with chemotherapy alone; $0.97 \pm 0.22 \mathrm{~cm}(\mathrm{p}=0.41)$ in the combined group chemotherapy+Maitake and $0.87 \pm 0.15 \mathrm{~cm}(\mathrm{p}=0.29)$ in the group of mice treated with Maitake Pro4X alone (Figure 2A). No significant differences $(p>0.05)$ were found in the tumour sizes at day 8th or 15th of treatment in any experimental group. Furthermore, at the end of the treatment (22 days of tumorigenesis), no significant differences $(p>0.5)$ were found in the size of tumour in any group $(1.23 \pm 0.42 \mathrm{~cm} 1.34 \pm$ $0.15 \mathrm{~cm}$ or $1.16 \pm 0.44 \mathrm{~cm}$ in chemotherapy group; in combined treatment group and in the group treated with maitake alone, respectively (Figure $2 \mathrm{~A}$ ). Figure $2 \mathrm{~B}$ shown the pictures of abdominal area indicating the breast tumour of each mouse from the beginning to the end of treatment in each assayed condition.

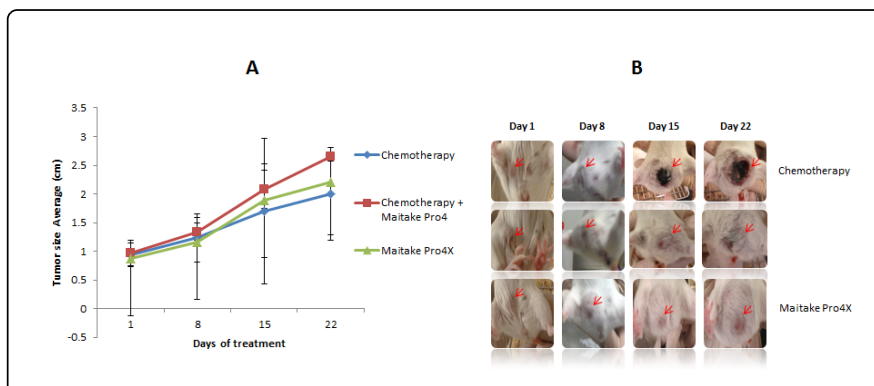

Figure 2: Effect of maitake as coadyuvant with chemotherapy in tumour grow size. A represents a graphics of tumour size average $(\mathrm{cm})$ after 1, 8, 15 and 22 days of treatment. Blue line represents the chemotherapy treatment, red and green line represents the Maitake Pro4X treatment with or without chemotherapy. B represents the abdominal area of mice from every condition after 1, 8, 15 and 22 days after treatment. Red arrows indicate the location of mammary tumour.

\section{Effect of Maitake Pro4X and chemotherapy on tumour necrosis}

The in vivo macroscopic inspection of mammary tumours during treatment showed that the tumours treated with Pro4X Maitake were less aggressive and less ulcerative than those receiving chemotherapy (Figure 3B). Mice treated with Maitake Pro4X alone exhibited significantly less area of necrosis and ulceration $\left(0.12 \pm 0.20 \mathrm{~cm}^{2}\right.$, $\mathrm{p}<0.01)$ compared to those animals in the groups treated with chemotherapy with or without Maitake Pro4X $\left(0.85 \pm 0.22 \mathrm{~cm}^{2}\right.$ and $0.80 \pm 0.20 \mathrm{~cm}^{2}$, respectively) (Figures $3 \mathrm{~A}$ and $3 \mathrm{~B}$ ). 


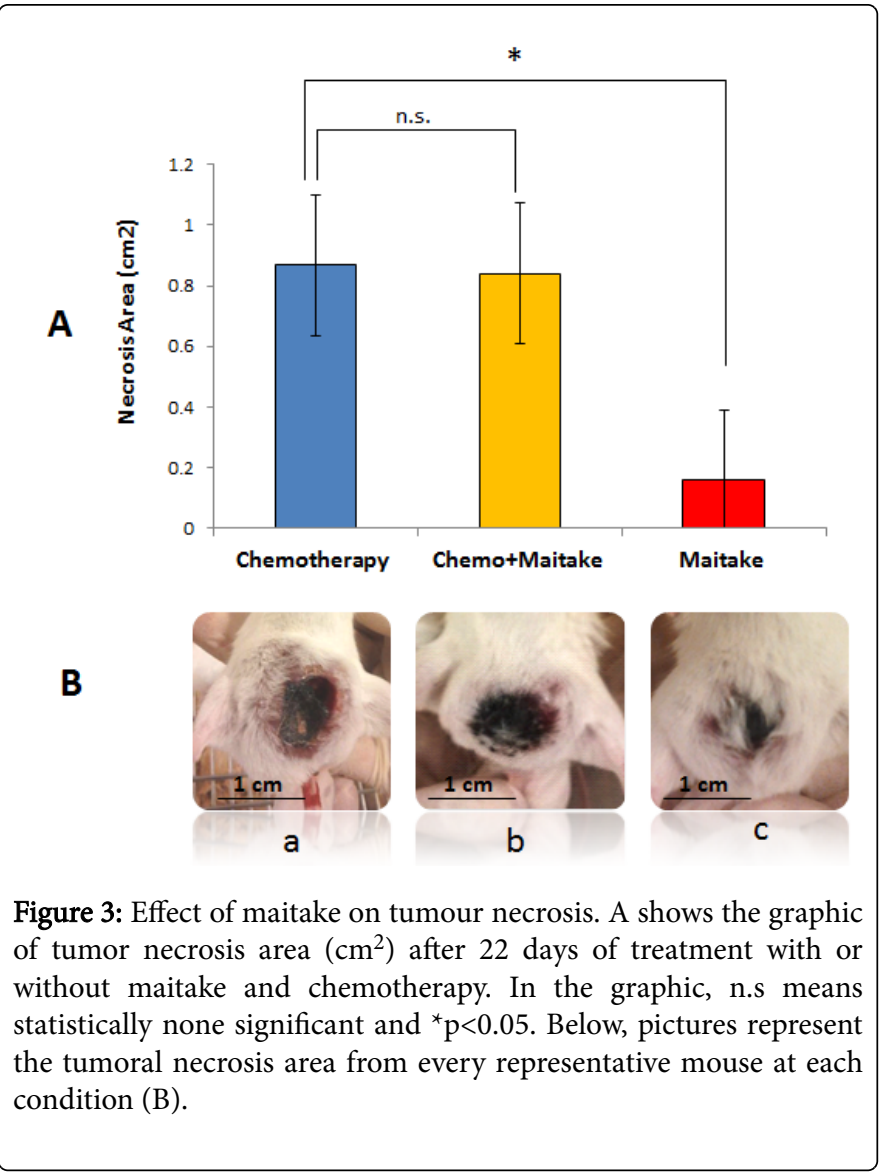

\section{Effect of Maitake Pro4X and chemotherapy on mortality}

Mortality was higher in the animals treated with chemotherapy alone, and achieves an average of $40 \pm 6.0 \%$ (Figure $4 \mathrm{~A}$ ), whereas in the groups treated with maitake alone or in combination with chemotherapy, mortality was significantly lower $(15 \pm 3.0 \%$, and $10 \pm$ $2.0 \%$, respectively with $\mathrm{p}<0.001$ ) (Figure $4 \mathrm{~A}$ ). It was interesting to note that $40 \%$ of the animals died because chemotherapy treatment after one week (Day 8, indicated with blank squares, Figure 4B), then mortality increase at $60 \%$ until the end of experiment. In the animals treated with combination of chemotherapy and Maitake Pro4X, we observed that mortality achieved up to $40 \%$ at the end of treatment (Figures $4 \mathrm{~A}$ and $4 \mathrm{~B})$. However, a significant reduction $(\mathrm{p}<0.001)$ were observed in the number of dead animals in the group treated with Maitake Pro4X alone (Figures 4A and 4B). Only two animals died at the end of treatment $(10 \pm 2.0 \%$, with $\mathrm{p}<0.001)$ in the group treated with Maitake Pro4X (Figure 4B).

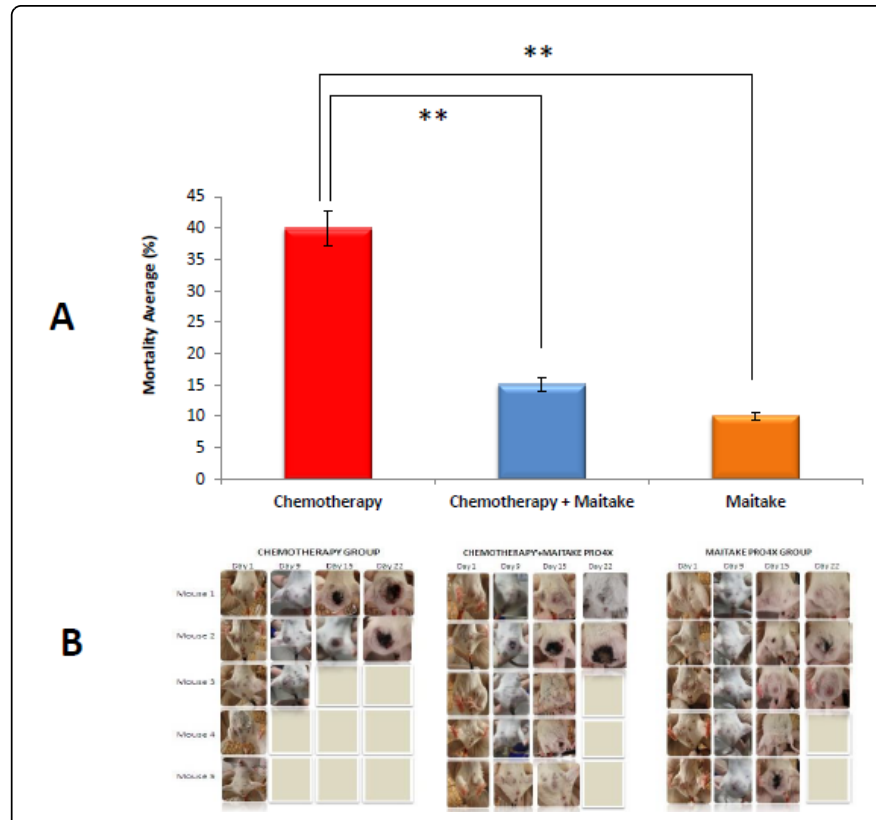

Figure 4: Effect on mortality after breast tumor treatment. Total mortality (\%) were measured after the end of treatment at any condition indicated in $\mathrm{A}$. ${ }^{* *}$ means $\mathrm{p}<0.01$. the graphic below (B) represents the abdominal mice pictures at each condition after 1,8 , 15 and 22 after treatment.

\section{Effect of Maitake Pro4X and chemotherapy on relative survival}

In order to determine whether the tumor treatment with Maitake Pro4X could improve mice relative survival, we determined the number of mice remaining alive after treatment. Figure 5 show the results at different times during the treatment; until day 21st of treatment, relative survival curve was similar in Maitake Pro4X groups with or without chemotherapy $(1.0 \pm 0.00$, and $1.0 \pm 0.0$ respectively), none deaths was registered in any group. Relative survival was lower in the chemotherapy group, since the first week (Day 8) were reduced until $40 \%$ (Figure 5); at day 15th of treatment was even lower and at the end of the experiment was cero $(0.00 \%)$, none of the animal were alive (Figure 5). The rate of relative survival in the combined treatment with Chemotherapy+Maitake Pro4X was reduced up to $40 \%$ at day 23rd after treatment and then were also null $0.00 \%$ at the end of experiment because all the mice died. Is clear to note the treatment with Maitake Pro4X (5 mg/kg) improved the relative mice survival, achieving up to $40 \%$ until de end of the experiment (Figure 5). 


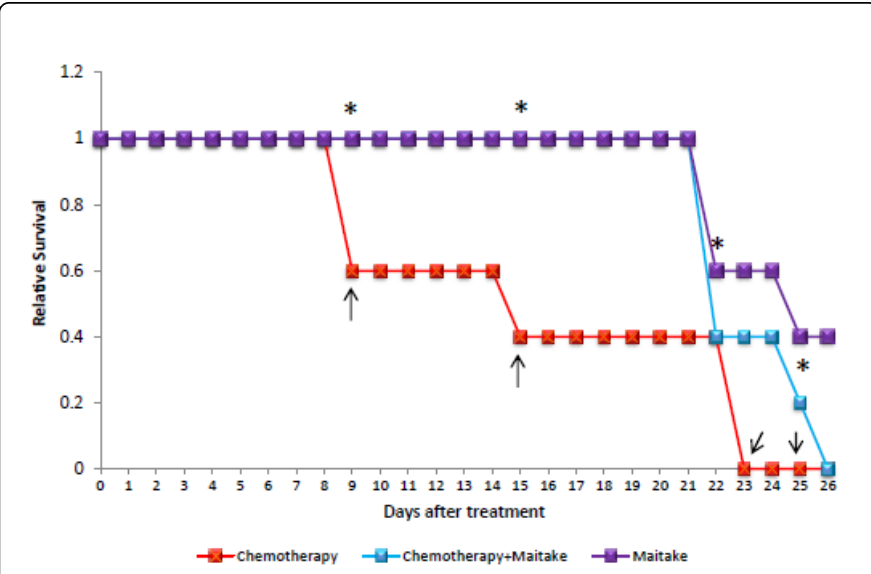

Figure 5: Overall survival percentage curve after breast tumour treatment. The graphic shows the percentage of overall survival of female BALBc mouse after chemotherapy treatment alone, in combination with Maitake Pro4X or Maitake Pro4x alone over 8 to 26 days of treatment. Overall survival indicates the number of mice that remained alive at the end of treatment (at 26 days) with respect to the total number of mice studied in each group. At each arrow time indication, ${ }^{\star}$ means $\mathrm{p}<0.01$.

\section{In vitro effect of Maitake Pro4X on cell death}

Tumour cell death values depending on the concentration of Maitake Pro4X Fraction D at 24, 48 and 72 hours of treatment are shown in Figure 6A, showing that the percentage of cell death were significantly increased depending on both the concentration of Maitake Pro4X and the duration of treatment. The highest percentage of cell death $(61.52 \pm 0.89 \%)$ corresponded to treatment with the highest dose of Maitake $(734 \mu \mathrm{g} / \mathrm{ml})$ for 72 hours, the longest treatment duration (Figure 6A). It is important to clarify here that, the $734 \mu \mathrm{g} / \mathrm{ml}$ of Maitake Pro4X employed in the cell cultured medium is equivalent to $5 \mathrm{mg} / \mathrm{Kg}$ in the animal treatment.

\section{In vitro effect of chemotherapy with cyclophosphamide and doxorubicin on cell death}

Figure 6B displays a graph of tumour cell death values plotted according to the concentration of the chemotherapeutic drugs used (doxorubicin and cyclophosphamide) for 24, 48 and 72 hours. Figure $6 \mathrm{~B}$ shows the cell death percentage at increased concentrations of the chemotherapeutic drugs. In all treatments (except in the lower dose), cell death was significantly higher (Student's t-test. $\mathrm{P} \leq 0.05$ ) relative to controls. We also found that the highest percentage of cell death $(80.75$ $\pm 2.66 \%)$ corresponded to the higher concentration of chemotherapy used $(40 \mu \mathrm{M}$ doxorubicin $+2.5 \mu \mathrm{M}$ cyclophosphamide). The optimal time of cytolytic action was also the longer treatment (72 hours) (Figure 6B).

In order to compare the effect of both Chemotherapy and Maitake on cell death at each concentration during 24 hours, 48 and 72 hours, Figure $6 \mathrm{C}$ were made. From those graphics were observed not significant differences in cell death at 24,48 or 72 hours between treatments at any concentration, except the highest dose used with chemotherapy that showed to be significantly different $(\mathrm{p}<0.05)$ with respect Maitake treatment at 24 and 48 hours, not at 72 hours.

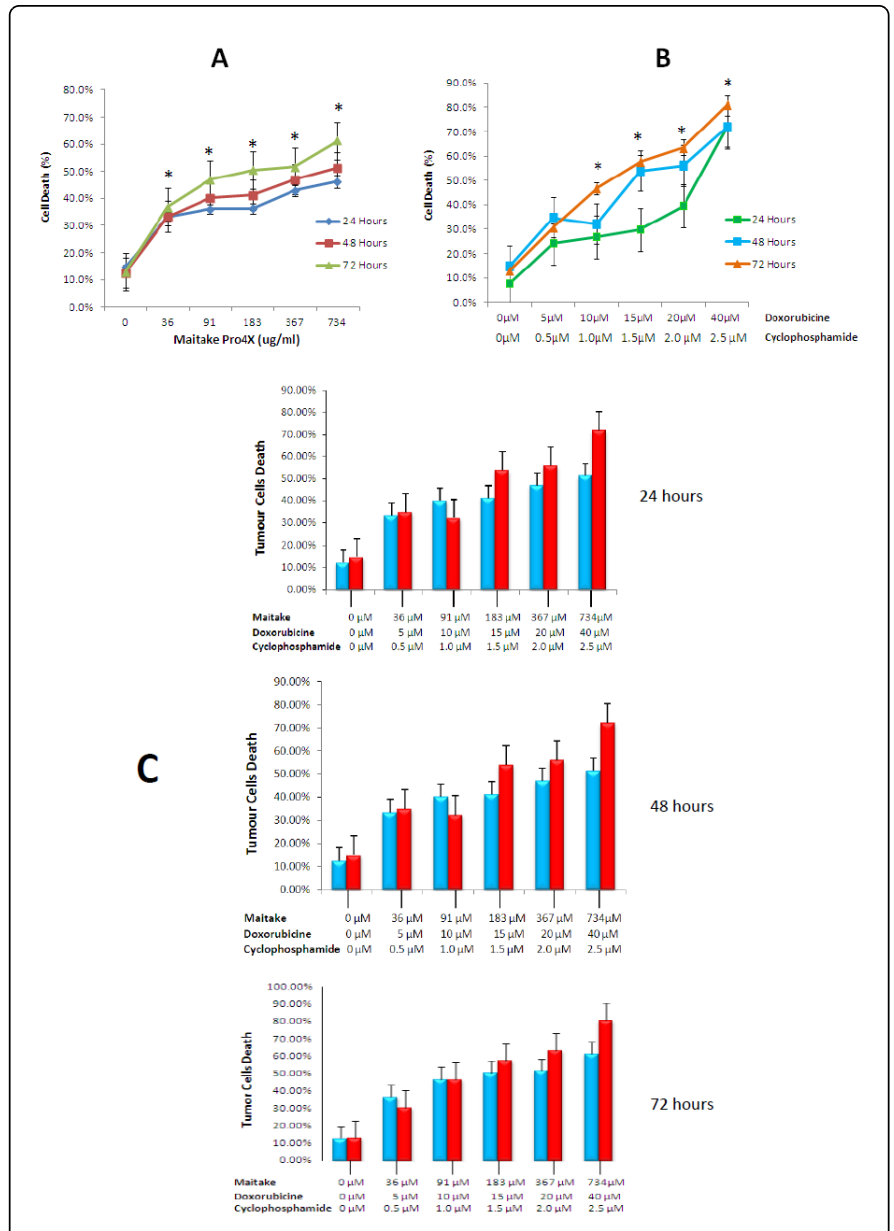

Figure 6: Dose-dependent LM3 cell death curves at 24, 48 and 72 hours after treatment. A: This figure shows the \% of tumour LM3 cells death after dose-dependent treatment with Maitake Pro4X after 24 hours (blue line), 48 hours (red line) and 72 hours (green line). B: This figure shows the tumour LM3 cells death \% after dosedependent treatment with chemotherapy after 24 hours (green line), 48 hours (blue line) and 72 hours (orange line). C: the graphics represents the effect on cell death at the comparative treatment of Maitake and Chemotherapy after 24 hours (upper graph), 48 hours (Middle graph) and 72 hours (bottom graph) of treatment. In the graphs, blue columns represent the Maitake Pro4X treatment and red columns represent the chemotherapy treatment at any increased dose.

\section{In vitro effect of Maitake D-fraction on normal human breast cells MCF-10F}

In order to demonstrate if Maitake D-fraction Pro4X has selectivity on cell death in tumor cells but not in normal breast cells, we measured the number of deaths MCF-10F cells after treatment at increase doses and at different times. Cells were incubated by triplicate with $\mathrm{D}$ Fraction at $37^{\circ} \mathrm{C}$ in controlled atmosphere with $5 \% \mathrm{CO}_{2}$ in serum free medium. At the end of treatment, cell deaths were determined by the technique of Trypan Blue exclusion assay, counting percentage of dead and percentage of live cells in Neubauer chamber. The assay was tested at increase concentrations of Maitake D-Fraction at 91, 183 and 367 
$\mathrm{ug} / \mathrm{ml}$ of culture medium during 24, 48 and 72 hours. All the experiments were done by triplicate. Surprisingly, treatment of cells normal mammary MCF-10F cells, with increased concentrations of Dfraction did not caused significant increases in the percentage of cell death compared to control at any experimental dose (Figure 7).

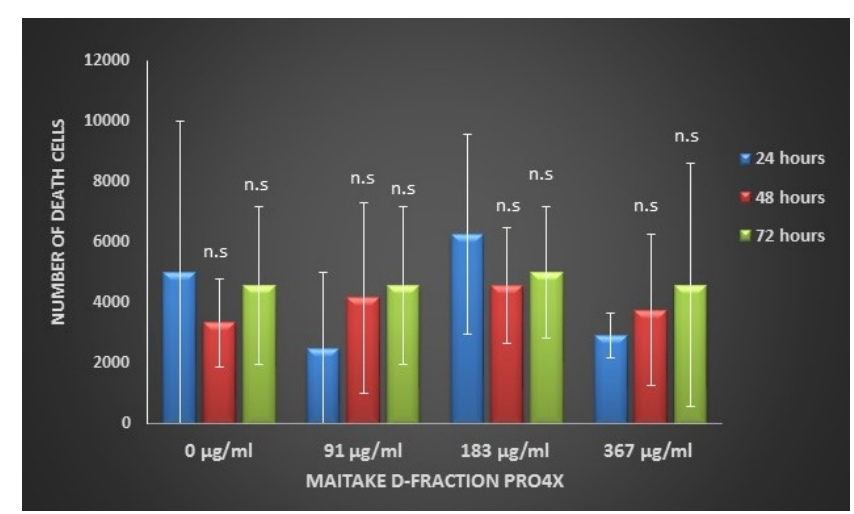

Figure 7: Cell death caused by different concentrations of Maitake D-fraction on MCF-10F cells at 24,48 and 72 hours of treatment. This figure shows the percentage of normal or non-malignant MCF-10F cells death after dose-dependent treatment with Maitake Pro4X after 24 hours (blue line), 48 hours (red line) and 72 hours (green line). Cell death was measured with method of Trypan Blue exclusion dye as indicated in methodology. The values represented the mean \pm correspond to S.D. $(n=3)$. In the figures, n.s means no significant differences were found with respect to control.

\section{Discussion}

Excessive tumour cell proliferation, an essential tumour process, is due to deregulation of cell growth. Because of the acquisition of mutations by cells, certain genes involved in the regulation of cell proliferation or differentiation become oncogenes that trigger tumorigenesis and developed cancer. Cells undergo uncontrolled proliferation and escape apoptosis, either via physiological pathways that induce apoptosis or by the inactivation of inhibitory pathways. The disruption of apoptosis can also contribute to the development of metastasis because it allows some tumour cells to survive in the bloodstream and to invade other tissues, allowing cells in suspension to evade apoptosis [32]. Therefore, finding compounds that cause apoptosis in tumour cells specifically is of particular interest. Many chemotherapy drugs act by inducing apoptosis in these cells but lack specificity and thus affect nearly all actively dividing cells. As mentioned previously, the antitumor properties of the Maitake DFraction are attributed to its immunomodulatory effect. Reports have also indicated that Maitake directly induce apoptosis in tumour cells such as prostate [33], stomach [34], kidney [35] and breast [36] cancer cells.

In this work, were studied the effects of the Maitake D-Fraction and chemotherapy (cyclophosphamid+doxorubicin) on cell death in murine breast cancer LM3 cells. Different concentrations of Maitake Pro4X alone or in combination with chemotherapy at different times were employed to study the effect on tumour cells in culture. The results show that both, Maitake and chemotherapy treatments, increased tumour cell death in a concentration- and time-dependent manner. Thus, the Maitake D-fraction treatment alone may have a chemotherapeutic effect by inducing cell death in a dose-dependent manner. In previous studies, we demonstrated that tumour MCF-7 cell death was induced by Maitake Pro4X via apoptosis [36]. Moreover, were observed that treatment with chemotherapeutic drugs increased cell death at a higher level compared with treatment with the Maitake D-fraction.

By another hand, we also demonstrate that the effect on cell death induced by Maitake was specific to breast tumour cells because not significant death was detected in the experiment employing normal breast MCF-10F cells.

Despite advances in the treatment of breast cancer, many obstacles remain unsolved. In many cases, the conventional treatment was ineffective due to resistance of the tumour to treatment or due to metastases. Moreover, existing therapies can produce adverse effects due to their specificity. For these reasons, finding a new treatment regimen, which helps patients to better tolerate while treating the cancer, inhibiting metastasis, increasing survival and improving patient quality of life is needed.

Thus, in this work was studied the effect of orally administered Maitake D-fraction in mammary tumourigenesis in BALBc mice. As chemotherapy, Maitake Pro4X alone or in combination with chemotherapy treatment did not significantly reduce the tumour size $(\mathrm{cm})$ in BALBc mice. By contrast with our results, Hishida et al. [22], has been reported a $64 \%$ inhibition of tumour growth in $\mathrm{C}_{3} \mathrm{H} / \mathrm{HeN}$ with breast carcinoma mice that were orally administered with 3.0 $\mathrm{mg} / \mathrm{ml} \mathrm{D}$-Fraction (directly extracted from the Maitake fruiting body). However, in the present work, a commercial product of Maitake DFraction Pro4X was used. Moreover, the orally administered chemotherapy at a dose of $4 \mathrm{mg} / \mathrm{kg}$ of doxorubicin and $80 \mathrm{mg} / \mathrm{kg}$ of cyclophosphamide did not reduce the tumour size either. These results are in contrast with Ottewell et al. [37], who inoculated nude MF1 mice with human MDA-MB-436 breast cancer cells. After 7 days of weekly-administered doxorubicin $(2 \mathrm{mg} / \mathrm{kg}$ by intravenous injection, a classical method of chemotherapy administration), they evaluated tumour growth; significant differences were observed in the tumour volume of animals receiving doxorubicin compared with that of control animals. Another study from Riwanto et al. [38] found a reduction of tumour growth in $\mathrm{C} 3 \mathrm{H}$ mice that were inoculated with breast cancer cells and that were treated intravenously with $0.013 \mathrm{mg}$ of cyclophosphamide plus $0.0156 \mathrm{mg}$ of doxorubicin. Here is necessary to talk about why not differences were found in the reduction of the tumour volume after treatment of chemotherapy alone or in combination with Maitake D-Fraction Pro4X. Not differences were found in the breast-tumour volume from BALBc mice treated with Maitake alone, either. These results are support by our recent findings [39], whether no significant reduction in the breast tumour volume were found after oral treatment during cancer prevention with Maitake Pro4X (5 mg/kg) of BALBc mice compare to the control untreated. However, histological studies of those breast tumours revealed that Maitake Pro4X treatment reduce the malignancy of the tumour, acquiring benign characteristics, such as be full of liquid inside, with net borders and with a small mitotic index. In contrast the breast tumour from the control group that have the characteristic of tumour malignancy with irregular borders, solid aspect and high mitotic index.

By another hand, higher mortality in the group of mice treated with chemotherapy alone was found. However, the combination of chemotherapy with Maitake Pro4X prevented death from toxicity caused by chemotherapy itself. Furthermore, mortality was significantly lower in the group treated with Maitake Pro4X alone. This 
can be explained by considering the adverse effects of treatment with cyclophosphamide and doxorubicin $[9,15,16]$. In agreement with those results, Baselga et al. [40] reported that mortality was higher $(21 \%$ compared with $13 \%$ in the control animals) in athymic BALBc mice treated with intraperitoneal injections of doxorubicin $(100 \mathrm{mg} / 20 \mathrm{~g}$ body weight) after 15 days of treatment. Thus, the rate of mortality induced by doxorubicin was high [40].

\section{Conclusion}

In this work, we demonstrated that treatment with Maitake Dfraction stimulates cell death in LM3 tumour cells in culture. Furthermore, these results suggest that the administration of Maitake D-fraction Pro4X alone or in combination with chemotherapy increases the overall survival of mice with breast tumours. Interestingly, although it could protect against the adverse effects of chemotherapy, such as reduce mortality, increase the overall survival, and reduce tumour necrosis and malignancy. The beneficial effects of Maitake Pro4X could be useful for the treatment of cancer patients receiving chemotherapy or radiation.

\section{Competing Interest}

The authors declare that they have no competing interests.

\section{Authors' Contributions}

$\mathrm{DAB}$ and $\mathrm{ARD}$ carried out most of the in vitro and in vivo assay studies described in this manuscript. BB participated in the animal checks, paraffin block preparation, RNA isolation and PCR amplification. GAB is the PI of this project wrote the manuscript and conducted the final editing of this manuscript.

\section{Acknowledgements}

We thank Dr. Maria Marta Corte from the Laboratory of Pathology, Bahia Blanca-Argentina for her very important contribution to the histological analysis in this work. We also thank CONICET, Argentina's National Council for Research, for the funding to develop this project in our laboratory. Finally, we thank Dr. Tomas Santa Coloma from BIOMED-UCA for his valuable contributions in the editing and interpretation of this manuscript.

\section{References}

1. Vieira SC (2012) Oncología Básica.

2. Alonso E, Orozco M, Nieto A, Le Moglie G, Obiol D, et al. (2010) First molecular study and analysis of polymorphisms in the BRCA1 gene in patients with breast cancer in Argentina. Latin American Congress of Genetics (ALAG), Viña del Mar, Chile.

3. Scully OJ, Bay BH, Yip G, Yu Y (2012) Breast cancer metastasis. Cancer Genomics Proteomics 9: 311-20.

4. Lanore D, Delprat C (2004) Chemotherapy anticancerosa.

5. Skeel RT, Khleif SN (2011) Handbook of cancer chemotherapy (8thedn). Lippincott Williams \& Wilkins-Philadelphia, PA, USA.

6. Dy GK, Adjei AA (2013) Understanding, recognizing, and managing toxicities of targeted anticancer therapies. CA Cancer J Clin 63: 249-79.

7. Zhang M, Liu X, Li J, He L, Tripathy D (2007) Chinese medicinal herbs to treat the side-effects of chemotherapy in breast cancer patients. Cochrane Database Syst Rev 2: CD004921.
8. Partridge AH, Burstein HJ, Winer EP (2001) Side effects of chemotherapy and combined chemohormonal therapy in women with early-stage breast cancer. J Natl Cancer Inst Monogr 30: 135-42.

9. Aubel-Sadron G, Londos-Gagliardi D (1984) Daunorubicin and doxorubicin, anthracycline antibiotics, a physicochemical and biological review. Biochimie 66: 333-52.

10. Arcamone F, Cassinelli G, Fantini G, Grein A, Orezzi P, et al. (1969) Adriamycin, 14-hydroxydaunomycin, a new antitumor antibiotic from $S$. peucetius var. caesius. Biotechnol Bioeng 11: 1101-10.

11. Balogh GA, Obiol D, Alonso E (2012) Maitake and its therapeutic actions in cancer.

12. Singal PK, Iliskovic N (1998) Doxorubicin-induced cardiomyopathy. New England Journal of Medicine 339: 900-905.

13. Chen ZC, Chen LJ, Cheng JT (2013) Doxorubicin-induced cardiac toxicity is mediated by lowering of peroxisome proliferator-activated receptor $\delta$ expression in rats. PPAR Res 2013: 456042.

14. Moura LR, Martins AC, da Rocha Vaz LA, Orpinelli SRT, da Silva TL, et al. (2013) Hydroalcoholic extract of pequi bark (Caryocar brasiliense) in rats submitted to the application of Doxorubicin. Ciência Rural 43: 100-106.

15. Li F, Ozkaya E, Akula K, De Sutter P, Oktay K (2012) Male and female fertility preservation. Human Reproduction 27: ii248-ii261.

16. Ahmed AR, Hombal SM (1984) Cyclophosphamide (Cytoxan). A review on relevant pharmacology and clinical uses. J Am Acad Dermatol 11: $1115-26$.

17. Anderson D, Bishop JB, Garner RC, Ostrosky-Wegman P, Selby PB (1995) Cyclophosphamide: Review of its mutagenicity for an assessment of potential germ cell risks. Mutat Res 330: 115-81.

18. Illana-Esteban C (2008) E L maitake (Grifola frondosa) and its therapeutic potential. Revista Iberoamericana de Micología 25: 141-144.

19. Lull C, Wichers HJ, Savelkoul HF (2005) Antiinflammatory and immunomodulating properties of fungal metabolites. Mediators Inflamm 2005: 63-80.

20. Brizuela MAG, Pérez L, Mansur M (1998) Basidiomycetes: New source of secondary metabolites. Revista iberoamericana de micología 15: 69-74.

21. Soumya Chatterjee GB, Kumar Basu S, Acharya K (2011) Antineoplastic effect of mushrooms: a review. Australian Journal of Crop Science (AJCS) 5: 904-911.

22. Hishida I, Nanba H, Kuroda H (1988) Antitumor activity exhibited by orally administered extract from fruit body of Grifola frondosa (maitake). Chem Pharm Bull (Tokyo) 36: 1819-27.

23. Demir G, Klein HO, Mandel-Molinas N, Tuzuner N (2007) Beta glucan induces proliferation and activation of monocytes in peripheral blood of patients with advanced breast cancer. Int Immunopharmacol 7: 113-6.

24. Brown GD, Herre J, Williams DL, Willment JA, Marshall AS, et al. (2003) Dectin-1 mediates the biological effects of beta-glucans. J Exp Med 197: 1119-24.

25. Deng G, Lin H, Seidman A, Fornier M, D'Andrea G, et al. (2009) A phase I/II trial of a polysaccharide extract from Grifola frondosa (Maitake mushroom) in breast cancer patients: immunological effects. J Cancer Res Clin Oncol 135: 1215-21.

26. Chan GC, Chan WK, Sze DM (2009) The effects of beta-glucan on human immune and cancer cells. J Hematol Oncol 2: 25.

27. Mayell M (2001) Maitake extracts and their therapeutic potential. Altern Med Rev 6: 48-60.

28. Nanba H (1997) Maitake D-fraction: Healing and preventive potential for cancer. J Orthomol Med 12: 43-49.

29. Carnevale RP, Proietti CJ, Salatino M, Urtreger A, Peluffo G, et al. (2007) Progestin effects on breast cancer cell proliferation, proteases activation, and in vivo development of metastatic phenotype all depend on progesterone receptor capacity to activate cytoplasmic signaling pathways. Mol Endocrinol 21: 1335-58.

30. Freshney RI (2011) Culture of animal cells: A manual of basic technique and specialized applications (6th edn). John Wiley \& Sons, Inc., USA. 
Citation: Braico DA, Deamicis AR, Brie B, Balogh GA (2017) Comparative Effect of Maitake Pro4x with Chemotherapy Breast Cancer Treatment. Biol Med (Aligarh) 9: 394. doi:10.4172/0974-8369.1000394

Page 8 of 8

31. Stokes M (1996) Statistical enhancements in release 6.12 of the SAS system. NC Statistical Analysis Systems Institute. Inc.

32. Andreu GP, Casaña PH, Hernández RD (2005) Apoptosis and cellular senescence: tumor suppressor mechanisms. Revista Cubana de Medicina 44: 1-2.

33. Fullerton SA, Samadi AA, Tortorelis DG, Choudhury MS, Mallouh C, et al. (2000) Induction of apoptosis in human prostatic cancer cells with beta-glucan (Maitake mushroom polysaccharide). Mol Urol 4: 7-13.

34. Shomori K, Yamamoto M, Arifuku I, Teramachi K, Ito H (2009) Antitumor effects of a water-soluble extract from Maitake (Grifola frondosa) on human gastric cancer cell lines. Oncol Rep 22: 615-20.

35. Alexander B, Fishman AI, Eshghi M, Choudhury M, Konno S (2013) Induction of Cell death in renal cell carcinoma with combination of Dfraction and vitamin C. Integr Cancer Ther 12: 442-8.

36. Soares R, Meireles M, Rocha A, Pirraco A, Obiol D, et al. (2011) Maitake (D fraction) mushroom extract induces apoptosis in breast cancer cells by BAK-1 gene activation. J Med Food 14: 563-72.
37. Ottewell PD, Mönkkönen $\mathrm{H}$, Jones M, Lefley DV, Coleman RE, et al. (2008) Antitumor effects of doxorubicin followed by zoledronic acid in a mouse model of breast cancer. J Natl Cancer Inst 100: 1167-1178.

38. Riwanto I, Budijitno S, Dharmana E, Handojo D, Prasetyo SA, et al. (2011) Effect of phaleria macrocarpa supplementation on apoptosis and tumor growth of $\mathrm{C} 3 \mathrm{H}$ mice with breast cancer under treatment with adriamycin-cyclophosphamide. Int Surg 96: 164-70.

39. Roldan-Deamicis A, Alonso E, Brie B, Braico DA, Balogh GA (2016) Maitake Pro4X has anti-cancer activity and prevents oncogenesis in BALBc mice. Cancer Med 5: 2427-41.

40. Baselga J, Norton L, Masui H, Pandiella A, Coplan K, et al. (1993) Antitumor effects of doxorubicin in combination with anti-epidermal growth factor receptor monoclonal antibodies. J Natl Cancer Inst 85: 1327-33. 